\title{
WestVirginiaUniversity
}

THE RESEARCH REPOSITORY @ WVU

Graduate Theses, Dissertations, and Problem Reports

2008

\section{Social anxiety and facial affect recognition in preschool children}

Chelsea M. Ale

West Virginia University

Follow this and additional works at: https://researchrepository.wvu.edu/etd

\section{Recommended Citation}

Ale, Chelsea M., "Social anxiety and facial affect recognition in preschool children" (2008). Graduate Theses, Dissertations, and Problem Reports. 2621.

https://researchrepository.wvu.edu/etd/2621

This Thesis is protected by copyright and/or related rights. It has been brought to you by the The Research Repository @ WVU with permission from the rights-holder(s). You are free to use this Thesis in any way that is permitted by the copyright and related rights legislation that applies to your use. For other uses you must obtain permission from the rights-holder(s) directly, unless additional rights are indicated by a Creative Commons license in the record and/ or on the work itself. This Thesis has been accepted for inclusion in WVU Graduate Theses, Dissertations, and Problem Reports collection by an authorized administrator of The Research Repository @ WVU. For more information, please contact researchrepository@mail.wvu.edu. 
Social Anxiety and Facial Affect Recognition in Preschool Children

\author{
Chelsea M. Ale, B.A.
}

Thesis submitted to the Eberly College of Arts and Sciences

at West Virginia University

in partial fulfillment of the requirements

for the degree of

Master of Science
in
Psychology

Tracy L. Morris, Ph.D., Chair Steven Branstetter, Ph.D.

Julie Hicks Patrick, Ph.D.

Department of Psychology

Morgantown, West Virginia 2008

Keywords: Social anxiety, Behavioral inhibition, Preschool, Affect recognition 


\section{ABSTRACT \\ Social Anxiety and Facial Affect Recognition in Preschool Children}

\section{Chelsea M. Ale}

Previous research relating anxiety and facial affect recognition, focusing mostly on schoolaged children and adults, has yielded mixed results. The current study sought to demonstrate an association among behavioral inhibition and parent-reported social anxiety, shyness, social withdrawal and facial affect recognition performance using the Diagnostic Analysis of Nonverbal Accuracy Scale in 30 preschool children, ages 4 years to 5 years 8 months. Results indicated that social anxiety, social withdrawal, shyness, and behavioral inhibition together account for $25 \%$ of the variance in facial affect recognition performance, although this proportion was not statistically significant $r^{2}=.25, F(4,24)=1.95, p=.13$. A limit of the investigation was the relatively small sample size. Further studies with larger samples are required to better understand the possible association. 


\section{ACKNOWLEDGEMENTS}

Thanks to the Department of Psychology for project funding through the Alumni Fund grant program. I am fortunate to be in a department which values research and is able to support its students in this way.

Thanks to Chad Brice, a perfect stranger, and to Daniel Chorney for their assistance collecting data. I would also like to thank Kathy Zimmerman for opening her doors and allowing me to learn about real-life preschoolers as I developed this project. Kathy's dedication to children and interest in research issues made for an ideally productive learning environment.

A special thanks to my advisor, Tracy Morris, for her patience and support from the first literature search through submission. Her knowledge, professionalism, wit, and drive inspire me daily. It is my challenge to learn as much as I can from her. 


\section{TABLE OF CONTENTS}

TITLE PAGE

ABSTRACT

ACKNOWLEDGEMENTS

iii

TABLE OF CONTENTS

iv

LIST OF TABLES

vi

LIST OF FIGURES

vii

$\begin{array}{ll}\text { INTRODUCTION } & 1\end{array}$

$\begin{array}{ll}\text { SOCIAL ANXIETY IN EARLY CHILDHOOD } & 1\end{array}$

BEHAVIORAL INHIBTION

$\begin{array}{ll}\text { SHYNESS } & 3\end{array}$

$\begin{array}{ll}\text { SOCIAL WITHDRAWAL } & 3\end{array}$

SOCIAL COMPETENCE AND NONVERBAL COMMUNICATION 4

$\begin{array}{ll}\text { FACIAL AFFECT RECOGNITION } & 5\end{array}$

$\begin{array}{ll}\text { HYPOTHESES } & 7\end{array}$

$\begin{array}{ll}\text { METHOD } & 7\end{array}$

$\begin{array}{ll}\text { PARTICIPANTS } & 7\end{array}$

$\begin{array}{lc}\text { MEASURES } & 8\end{array}$

$\begin{array}{ll}\text { PROCEDURE } & 10\end{array}$

RESULTS

PRELIMINARY ANALYSES 11

$\begin{array}{ll}\text { HYPOTHESIS } & 13\end{array}$

$\begin{array}{ll}\text { EXPLORATORY ANALYSES } & 13\end{array}$

$\begin{array}{ll}\text { DISCUSSION } & 14\end{array}$

$\begin{array}{ll}\text { FINDINGS } & 14\end{array}$ 
LIMITATIONS

$\begin{array}{ll}\text { IMPLICATIONS AND FUTURE DIRECTIONS } & 16\end{array}$

$\begin{array}{ll}\text { REFERENCES } & 18\end{array}$

$\begin{array}{ll}\text { TABLES } & 24\end{array}$

$\begin{array}{ll}\text { FIGURES } & 31\end{array}$

$\begin{array}{ll}\text { APPENDICES } & 32\end{array}$ 


\section{LIST OF TABLES}

TABLE 1: DEMOGRAPHICS FOR TARGET VARIABLES 24

TABLE 2: DANVA2 ACCURACY SCORES

TABLE 3: PAIRED SAMPLES COMPARISONS OF AFFECT WITHIN DANVA2 SUBTEST 26

TABLE 4: PAIRED SAMPLES COMPARISONS OF AFFECT BETWEEN ADULT $\begin{array}{ll}\text { AND CHILD DANVA2 SUBTEST } & 27\end{array}$

TABLE 5: ANALYSIS OF VARIANCE FOR DEMOGRAPHIC VARIABLES BY DANVA2 ACCURACY

TABLE 6: MEANS, STANDARD DEVIATIONS, AND INTERCORRELATIONS FOR FACIAL AFFECT RECOGNITION AND SOCIAL ANXIETY VARIABLES

TABLE 7: REGRESSION ANALYSIS SUMMARY FOR SOCIAL ANXIETY VARIABLES RELATING TO FACIAL AFFECT RECOGNITION 


\section{LIST OF FIGURES}

FIGURE 1: GENDER BY LATENCY TO SPEAK 


\section{SOCIAL ANXIETY AND FACIAL AFFECT RECOGNITION IN PRESCHOOL CHILDREN}

The pattern of social wariness and avoidance known as social anxiety is a constellation of shyness, behavioral inhibition, and social withdrawal (Morris, 2001; Rubin \& Asendorpf, 1993). With significant impairment and distress, these behaviors make up Social Anxiety Disorder (SAD) which is characterized by a persistent fear of social or performance situations in which an individual fears acting in an embarrassing or humiliating way on exposure to evaluation or scrutiny by others (American Psychiatric Association, 1994). While SAD reaches the highest proportions in adulthood (Grant, Hasin, Blanco, et al., 2005), social anxiety typically begins in childhood. In a study conducted out of primary care settings, Chavira, Stein, Bailey, and Stein (2004) found that $18.9 \%$ of parents of 8-12 year old children reported their child had some social anxiety. These high rates of subclinical social anxiety in childhood are consistent with many adults with SAD reporting having been shy and socially anxious their whole lives. Asendorpf (1989) supports an additivity hypothesis for the development of social anxiety, stating that the "early form of inhibition continues through adulthood and simply adds up with an additional social-evaluative inhibition that may or may not arise in social interaction with strangers, depending on whether people care much about the image they convey to the stranger." High levels of trait anxiety may occur early in childhood, even though Social Anxiety Disorder is not often diagnosed until later in childhood or into adolescence.

\section{Social Anxiety in Early Childhood}

It is particularly important to understand the development, course, and treatment of anxiety in children as early as possible in order to minimize its interference with normal development (Morris, 2004; Ollendick \& Hirschfeld-Becker, 2002; Warren, Huston, Egeland \& Sroufe, 1997). There has been very little research on the prevalence of anxiety in early childhood, in part due to the dearth of preschool anxiety assessment tools. Spence and colleagues (2001) created the Spence Preschool Anxiety Questionnaire in order to examine the structure of anxiety in 2.5 to 6.5 
year old children. Results indicated that, among other anxieties, mothers report that their young children do experience social anxiety.

When examining preschool aged children who may be socially anxious, generally the literature speaks in terms of temperament and at-risk behaviors rather than diagnostic criteria. Behavioral inhibition, shyness, and social withdrawal in young children have been suggested as precursors to anxiety disorders, specifically social anxiety disorder, in later childhood and adolescence (Biederman et al., 2001; Rubin \& Asendorph, 1993; Rubin \& Burgess, 2001). While these terms often are used interchangeably, albeit perhaps inaccurately, they may each contribute distinct pieces to the development of anxiety.

\section{Behavioral Inhibition}

Behavioral inhibition is construct related to child temperament and is characterized by wariness and fearfulness upon encountering novel situations (Garcia Coll, Kagan \& Reznick, 1984; Rubin \& Asendorpf, 1993). Approximately 15 percent of preschool-aged children are identified as behaviorally inhibited (Egger \& Angold, 2006). First studied by Kagan and colleagues through a series of behavioral observations with infants, behavioral inhibition is thought to be reflective of the threshold of excitability in the limbic structure (Kagan, Reznick, \& Snidman, 1990). Kagan and colleagues (Garcia Coll et al., 1984; Kagan, Reznick, Snidman, Gibbons \& Johnson, 1988) have described two extremes in terms of children with no reticence in novel situations or with a high threshold for excitability ("Uninhibited") and, at the other extreme, children who are consistently excessively wary in novel situations or have a low threshold for excitability ("Inhibited"). Although over time it is most stable at these extremes (Kagan et al., 1988), many researchers examine behavioral inhibition as a continuous construct. By studying the continuum of behavioral inhibition, we may gain a better understanding of the complex behaviors which may be associated with anxiety. A growing body of literature links behavioral inhibition, in concert with parenting factors, to the development of social anxiety in childhood and adolescence (Biederman 
et al., 2001; Biedel, Turner \& Wolf, 1996; Morris, Hirshfield-Becker, Henin \& Storch, 2004; Rubin \& Burgess, 2001).

\section{Shyness}

Although shyness is used in common language to define behavior, research definitions have been refined over the years. Zimbardo (1977) defined shyness as "a fear of negative evaluation that was sufficient to inhibit participation in desired activities and that significantly interfere with the pursuit of personal or professional goals" (as cited in (Henderson \& Zimbardo, 2001). These researchers conceptualize behavioral inhibition as a precursor to shyness. Rubin and Asendorpf (1993) distinguish shyness as being inhibition in specific response to novel social stimuli. While shyness can be experienced at the state or trait level, the current study is concerned with the trait characteristic of shyness.

Asendorpf (1989) found that when approached by a confederate in a waiting room, fear of being evaluated and unfamiliarity of the confederate both contributed independently to college students' report of trait shyness. Participants who reported high trait shyness also attributed more negative thoughts to the confederate. Even though the behaviors associated with shyness share many characteristics of social anxiety, social anxiety involves an avoidant response which is unnecessary for shyness. In a longitudinal study examining predictors of internalizing behavior from age 5 through 15, Leve, Kim and Pears (2005) found that fear and shyness, in association with parental discipline, was a significant predictor of internalizing behavior in adolescence for all boys and for young girls.

\section{Social Withdrawal}

Social withdrawal refers to the "consistent display of solitary behavior when encountering familiar and/or unfamiliar peers." (Rubin \& Asendorpf, 1993). Social withdrawal may be driven by a lack of interest in peer interactions or by reticence to interact with peers despite motivation 
(Coplan, Prakash, O'Neil, \& Armer, 2004). For the latter group, social anxiety may interfere with their ability to join-in with peers resulting in solitary play (Rubin, 1982).

Consistent social isolation can have both short and long term effects on a child. Fourth through sixth graders who were rated by peers as socially withdrawn reported lower general selfesteem (Hymel, Woody, \& Bowkr, 1993). In a five year follow-up study of children identified as socially withdrawn at age five, these children were perceived as more anxious and less liked by peers than their non-socially withdrawn cohort (Ollendick,1990).

\section{Social Competence and Nonverbal Communication}

Social anxiety can hinder social and emotional development throughout childhood, increasing a child's risk for maladjustment and mental health problems throughout the lifetime (Morris et al., 2004). Specifically, early childhood is a crucial period in social development. During preschool, children learn to interact with peers, develop emotional understanding, and negotiate social situations (Denham et al, 2003; Halberstadt, Denham \& Dunsome, 2001). Mastery of these developmental competencies prepares the child for future successes in peer relations (Denham et al., 2003). Preschoolers who exhibit more socially anxious behaviors are often rated by teachers as less prosocial and more withdrawn, even though these same children may want to engage with their peers (Coplan et al., 2004). These children tend to avoid social interactions and in doing such may not gain basic social skills.

Many social subtleties are communicated through facial expressions and body language. From infancy, children examine the face of their caregivers in order to better understand their environment. This is clearly exemplified by the Still-Face Effect (Tronick, Als, Adamson, Wise, \& Brazelton, 1978), when most infants show a strong reaction to their caregiver's withdrawal of facial emotion. By preschool, while children are refining their decoding abilities, they still examine the face as a whole, rather than examining the parts individually. As their interpretation of facial emotion becomes more complex and they mature into childhood, adolescence, and adulthood 
their ability to isolate certain parts of the face (e.g., eyes) becomes increasingly refined (Pellicano \& Rhodes, 2003). Most children's abilities to recognize different affective stimuli increases throughout childhood as well. They begin identifying happy faces accurately in preschool and do not develop full accurate recognition of fearful facial stimuli until around age 10 (Philippot \& Feldman, 1990). Denham and colleagues (2003) assert that "children who can identify an expression on a peer's face or comprehend the emotions elicited by common social situations are more likely to react prosocially to their peers' displays of emotion." Facial affect recognition may be a key component of emotional and social development.

\section{Facial Affect Recognition}

In a non-clinical sample of 4 to 15 year olds, Herba and colleagues (2006) found a significant positive relation of age and emotion recognition accuracy. Within this sample, the young children (4 to 6 year olds) were most accurate in labeling fearful and happy faces. The relation of age and facial affect recognition abilities suggests that young children are rapidly developing their emotional and social abilities, perhaps beginning with the most intense emotions.

Nowicki and Mitchell (1998) found a positive relation of receptive nonverbal accuracy and social competence in preschoolers. However, they did not examine social anxiety, inhibition, or withdrawal for these children. Unlike children with Asperger's Syndrome and Autism, who show clear deficits in emotional processing (Ashwin, Wheelwright, \& Baron-Cohen, 2006), there are mixed results regarding the affect recognition abilities of children with social anxiety. One published study has found facial affect recognition deficits for 9 to 15 year old children and adolescents diagnosed with SAD compared to non-anxious peers (Simonian, Beidel, Turner, Berkes, \& Long, 2001). This study differed from the other studies presented herein in its facial stimuli. Simonian and colleagues used the Pictures of Facial Affect (Ekman \& Friesen, 1976), whereas most other studies have used the Diagnostic Analysis of Nonverbal Accuracy (DANVA; 
(Nowicki \& Duke, 1994) stimuli. It is unclear whether the methodological differences contributed to the divergent results or whether other variables may be in play.

Examining the abilities of socially anxious school-age children, Melfsen and Florin (2002) found no difference in affect recognition accuracy compared to non-anxious peers. They did report that children with greater social anxiety had longer reaction times than the non-clinical group. Although attentional processes were not examined, the findings suggest that children with higher social anxiety may examine faces more closely than their less anxious peers.

Ladouceur and colleagues (2005) found that 8 to 16 year olds with an anxiety disorder, Major Depressive Disorder, or comorbid anxiety and depression recognized facial emotion differently than non-clinical controls. Increasing anxiety in 6 to 10 year old children has been associated with greater accuracy in searching for angry and happy faces among distracting stimuli than searching for neutral faces (Hadwin et al., 2003), supporting a hypervigilance theory for facial cues in anxious children. This finding was not replicated by the researchers for depressed or nonclinical children (Nowicki \& Carton, 1997), suggesting that this hypervigilance may be a unique anxiety process.

While there is still debate as to whether children and adolescents who experience social anxiety show different abilities in labeling facial affect than less anxious individuals, the literature largely supports hypervigilant emotional processing in adolescents and school aged children with both clinical and subclinical levels of anxiety. There is a surprising gap in research focusing on facial affect recognition in preschool children. Preschool is the crucial period for development of social and emotional competence in the peer arena. By better understanding how social anxiety might contribute to differences in affect interpretation at this young age, early interventions and social skills training programs may be tailored to the needs of preschool-aged children. 
Hypotheses

The current study sought to demonstrate an association between social anxiety and facial emotion recognition abilities. Specifically, it was hypothesized that social anxiety, behavioral inhibition, and shyness would be positively related to accuracy in labeling facial affect. Scores on the Spence Preschool Anxiety Scale-Social Phobia Subscale, latency to speak, and the EASIII-Shyness and Sociability Subscales were hypothesized to explain a significant portion of the variance associated with total accuracy scores from the Diagnostic Analysis of Nonverbal Accuracy Scales.

Method

\section{Participants}

This study was conducted in conjunction with a dissertation project being conducted by Daniel Chorney. Primary procedures were common to both studies. Variables drawn from the questionnaire and observation task for the current study represent a subset of those from the larger investigation. The focus on facial affect recognition is unique to this study and the data associated with that task (described below) were not analyzed as part of the dissertation project.

Participants were recruited from three preschools in the Morgantown, West Virginia area. Since all four- and five-year-old children in the classrooms were eligible to participate a total of 99 parents were solicited. A total of 30 parents (30.3\%) over a six month period consented to participation in the study. Participating children ranged in age from 4 years 0 months to 5 years 8 months (15 girls and 15 boys, mean age of 4 years 5 months). The majority of parent respondents were mothers (89.7\%) and were highly educated (41.4\% held a graduate degree and $37.9 \%$ held a college degree). The sample was predominantly Caucasian (90\%) which is representative of the West Virginia population (94.9\%, U.S. Census Bureau, 2006). Upon completion of the study, a monetary donation was made to the preschool to supply new equipment or classroom resources. 


\section{Measures}

Diagnostic Analysis of Nonverbal Accuracy Scale—2 (Nowicki \& Duke, 1994). The Adult and Child Facial Expressions (DANVA2-AF and DANVA2-CF, respectively) DANVA2 subtests were used as the dependent measure in the present study. These subtests are two of seven DANVA tests which have been used with children to measure receptive nonverbal abilities. Each subtest consists of 24 photographs of male and female facial expressions of happy, sad, angry and fearful emotions (see Appendix A for sample photographs). In each emotion category, there are six photographs, three displaying high intensity emotion and three displaying low intensity emotion. The overall construct validity of the DANVA was examined in a sample of 1,001 children ages 6 through 10 years old (Nowicki \& Duke, 1994). Nowicki and Duke (1998) have used the facial expression DANVA2 subtests with 3 to 5 year old children. Scores have shown internal consistency as measured in children as young as 4 years old (average alpha $\mathrm{AF}_{\mathrm{AF}}=.71$, alpha $\mathrm{CF}_{\mathrm{C}}=$ .76) across 10 different studies (as reported in Nowicki \& Duke, 1998). Nowicki and Duke (1993) reported adequate test-retest reliability for the DANVA2-AF over a two month period for college students, $(\underline{r}=.84, \underline{n}=45)$. Test-retest reliability of the DANVA2-CF is reported as $\underline{r}=.88$ for college students and $\underline{r}=.74$ for third grade children over a 2-month period (Nowicki \& Carton, 1993). Since facial affect recognition is theoretically not directly related to intelligence, adequate discriminate validity was attained comparing DANVA2-AF scores to IQ scores and tests of general cognitive ability in a study using preschool children (Nowicki \& Mitchell, 1997).

Children's responses to the experimenter's prompt upon presentation of the stimulus (described below), was coded as accurate or inaccurate based on the DANVA2 scoring keys (Nowicki \& Duke, 2003). For the purposes of the primary analyses, percent of accurate responses on the DANVA2-AF and DANVA2-CF were combined into a Total DANVA2 Accuracy variable. 
Parent Report. Guardians completed a demographics questionnaire, providing socioeconomic and ethnicity information for the parent, his or her spouse (if applicable), and the child (see Appendix B).

The 20-item Emotionality, Activity, and Sociability (EAS) Temperament Survey (EAS-III; Buss \& Plomin, 1984) was administered to parent respondents. For the purposes of the study, the five-item Shyness subscale was analyzed to measure shyness and the five-item Sociability subscale was analyzed as a proxy of social withdrawal. The Shyness subscale (alpha $=.79$ to .83 ) and the Sociability subscale (alpha $=.60$ to .74 ) have shown adequate internal consistency in two samples of children ranging in age from four to 13 (Boer \& Westenberg, 1994; Mathiesen \& Tambs, 1999). While these two subscales were originally conceptualized as inverses of the same construct, factor analysis supports the construction of distinct subscales (Mathiesen \& Tambs, 1999).

Parents also were asked to complete the 27-item Spence Preschool Anxiety Scale (SPAS; Spence, Rapee, McDonald \& Ingram, 2001). The Social Phobia subscale data was analyzed as a measure of "social anxiety." The SPAS was adapted for developmental sensitivity from the Spence Anxiety Scale (Spence, 1998). Although reliability and validity data have not been reported yet for the SPAS, factor analysis suggests that the Social Phobia subscale represents a unique dimension of anxiety (explaining $40-60 \%$ of the variance) in preschool children as well as contributing to one higher order factor of anxiety in general (Spence, et al, 2001). In the current sample, the five Social Phobia subscale items had adequate internal consistency (alpha $=.67$ ).

Behavioral Observations. Children were engaged in the Stranger-child task (Bishop, Spence, \& McDonald, 2003), which was adapted from Asendorpf (1987). This task consists of three stages, Pre-Observation, Pre-Interaction Phase, and Interaction Phase (as described below), during which the child's behavior is coded. For the purposes of the study, only latency to speak during the Pre-Interaction Phase was targeted for analysis and served as a marker of 
behavioral inhibition. Two trained raters coded $20 \%$ of the behavioral observations and attained high reliability for latency to speak, $r=1.00$.

\section{Procedure}

A letter describing the study was sent home with the children along with routine materials distributed by the preschool. Parental consent forms and parent report measures were subsequently sent home with the children. Parents had the option of returning completed consent forms and questionnaires to the preschool in a sealed envelope or by postage-paid mail to the researchers directly. The facial recognition and behavioral observation tasks were conducted in the preschool setting once parental consent was obtained.

Facial Affect Recognition Task. Each participating child was taken into an empty classroom with a familiar young adult researcher. The child was led into the room to do a special activity and asked to sit in a child-sized chair across a small table from the researcher. The following script was spoken to the child once seated:

We think children can guess how grownups and children are feeling just by looking at their faces. I am going to show you some pictures of people's faces and I want you to guess how they are feeling. I want you to guess if they are feeling happy, sad, angry, or afraid. Do you know what these words mean? Can you tell me something that makes you happy? Something sad? Something angry? Something afraid? Good. Now I am going to show you some faces one at a time. I will show you each face for only a short time, so you have to look carefully. OK? Here's the first face. Ready? Is the person happy, sad, angry, or afraid?

The pictures were presented to the child for two seconds each. If the child did not answer within 10 seconds, the researcher repeated the prompt once then said, "Let's try another one," and proceeded to the next picture. Upon completion of the DANVA2 subtests, the child was offered a sticker for doing a good job regardless of task performance.

Stranger-child Task. The task began with the child being led to the observation room by a familiar young adult researcher. The researcher asked the child to sit on the mark on the rug and said to the child, "There are some blocks in here. You can play with them if you like." The researcher then left the child saying, "I'll be back in a little while. You stay here and play with these 
blocks." Approximately two minutes later, a stranger entered the observation room. The stranger was a Caucasian young-adult male confederate dressed in casual-smart clothes.

Upon the stranger's entry into the observation room, the Pre-Interaction phase began. The stranger walked directly into the room and on the rug approximately 2 meters from the child. As he sat down, the stranger briefly greeted the child and placed a bag of toys on the floor. After 5 seconds, the stranger began inspecting the toys without unpacking the bag and then briefly looked at the child with a slight smile three times. After 30 seconds the stranger began to slowly unpack the bag, placing the toys on the floor in front of him, then looked around the area for 1 minute. During the next 1.5 minutes he closely inspected and played with each toy in turn. Initiation latency (i.e., the time the child took to initiate verbal contact with the stranger) was recorded. The pre-interaction phase ended after 3 minutes if the child did not speak.

\section{Results}

Based on previous literature exploring facial affect labeling abilities in children, the current study aimed to demonstrate a relation between facial affect recognition and social anxiety, shyness, social withdrawal and behavioral inhibition with preschool children.

\section{Preliminary Analyses}

Normality - Descriptive statistics for all target variables are presented in Table 1. Before examining the primary hypothesis, frequencies and histograms were examined for each independent variable to asses the distribution of responses. Variance, skew and kurtosis were within normal limits for all measures. Inspection of the latency to speak data revealed a bimodal distribution of the observed time elapsed. For the purposes of the primary regression analysis the data were dummy coded into a dichotomous variable to represent those who spoke in fewer than 90s ( $n=22)$ and those who spoke after 90s or not at all $(n=7)$.

Missing data - The parent report measures contained very few missing data points. There were only two missing parent report data points in the entire dataset which affected the 
composition of the EAS-III-Sociability subscale and the SPAS—Social Phobia subscale. For both of these participants, the mean response on the scale was imputed to those data points. There were no missing DANVA2 items. One participant withdrew from the preschools before the Stranger-child Task could be completed. All other data points were collected from this child and the data are included for all analyses which did not rely on the Stranger-child task.

DANVA2 Performance- Because the DANVA2 has only been used with one sample of preschool children (Nowicki \& Mitchell, 1998) scores were examined before conducting further analyses. All children were able to complete the task. One child refused to speak to the researcher and nodded when the researcher said the choice affect label instead of responding verbally. Since social anxiety was of primary concern to the study and selective mutism can often be a symptom, these data were included despite the slight deviation from the standard DANVA2 protocol. While children did vary in their performance, anecdotally it seemed that they understood the demands of the task and responded thoughtfully.

Examination of the DANVA2 total affect recognition accuracy revealed that children were significantly better at labeling happy faces than sad, angry, and fearful faces (see Table 2). Children also performed better on the DANVA2-Child Faces $(M=61.11 \%)$ than on the DANVA2Adult Faces $(M=54.17 \%), t(29)=-2.70, p<.05$. Since there were differences in accuracy by both subtest and subscale, paired samples t-tests were conducted to compare the DANVA2-AF and DANVA2-CF subtests on affect subscales (see Table 3). Children identified happy faces $\left(M_{A F}=\right.$ 4.67, $\left.M_{C F}=5.07\right)$ and sad faces $\left(M_{A F}=2.63, M_{C F}=3.80\right)$ more accurately on the Child subtest than the Adult subtest, $t(29)=-2.05, p<.05$ and $t(29)=-4.05, p<.001$ respectively. There were not significant differences in accuracy between the subtests for angry and fearful facial stimuli.

Additionally, paired samples t-tests were conducted to compare affect subscales within each subtest (see Table 4). Children were significantly more accurate in labeling both happy child faces and happy adult faces than sad, angry $\left(M_{A F}=2.97, M_{C F}=2.27\right)$, and fearful $\left(M_{A F}=2.70\right.$, 
$\left.M_{C F}=3.53\right)$ on the respective subtests. Children were also more accurate in labeling sad child faces and fearful child faces than angry child faces.

Comparison of means using a one-way Analysis of Variance revealed no differences in DANVA2 accuracy for age, gender or ethnicity, as displayed in Table 5.

Hypothesis

In order to investigate associations among social anxiety, inhibition, social withdrawal, and facial emotion recognition performance, a linear regression was completed. The regression included the dependent variable of total affect recognition accuracy on the DANVA2 and the independent variables SPAS—Social Phobia Subscale (social anxiety), EASIII-Shyness Subscale (shyness), EASIII-Sociability Subscales (social withdrawal) and latency to speak (behavioral inhibition). Table 3 displays the means and correlations for all target variables. While there were significant correlations between the parent report independent variables (see Table 6), examination of colinearity diagnostic indices revealed adequate independence of each of the predictor variables. The standardized residual scores for the model indicate no outliers and that the model was a good fit for the data.

As displayed in Table 7, the regression model did not explain a significant portion of the variance in facial affect recognition performance, $r^{2}=.25, F(4,24)=1.95, p=.13$. However, social anxiety, as measured by the SPAS, was significantly related to variance in the facial affect recognition performance, $\beta=.61, \mathrm{t}(28)=2.39, \mathrm{p}=.02$.

A post hoc power analysis using the GPower program (Faul \& Erdfelder, 1992) revealed an actual power level of.62 in the regression analysis with four predictor variables, indicating an elevated risk of falsely accepting the null hypothesis.

\section{Exploratory Analyses}

Since relatively little is known about preschool social anxiety, especially in relation to facial affect labeling and specific threat cues, exploratory analyses were conducted. A chi-square 
analysis revealed a significant relation between gender and latency to speak, $\chi^{2}(1, N=29)=5.18$, $p=.03$. Specially, more boys spoke before 90 seconds $(n=14)$ than after 90 seconds or not at all $(n=1)$, see Figure 1. For girls, 8 spoke before 90 seconds and 6 spoke after 90 seconds or not at all.

\section{Discussion}

This study sought to further investigate the mixed findings relating affect recognition and anxiety (Hadwin et al., 2003; Ladouceur et al., 2005; Melfsen and Florin, 2002; Simonian, et al., 2001). This was one of the first studies to examine facial affect recognition and social anxiety during early social and emotional development in the preschool period.

\section{Findings}

The primary hypothesis that social anxiety would explain a significant portion of the variance in facial affect recognition performance was not supported by the regression model. Although the significant social anxiety beta weight for the SPAS suggests that there may be some relation, this is either not a significant predictor or there was insufficient power to detect a possible contribution. Future studies with larger samples are needed to further investigate a potential association.

Affect Labeling Performance-Examination of the DANVA2 revealed significant accuracy differences on the affective subscales. Children were significantly more accurate in labeling happy faces than sad, angry, or fearful faces. This is consistent with the developmental findings that happy is the first emotion to be recognized, followed by anger and sadness (Herba, et al, 2006; Philippot \& Feldman, 1990). Denham, et al. (2003) found that 3-5 year old children displayed more happy expressions than sad or angry expressions. It remains unclear whether children are exposed to more happy displays of emotion and so become more adept at deciphering these nonverbal cues or whether children's labeling of happy emotions lead to more displays of happiness. 
Children were also more accurate labeling child happy faces and sad faces than adult happy faces and sad faces. Children who attend preschool regularly may be exposed to a more diverse sampling of children's affective expression and may be more familiar with only specific adult faces (i.e., caregivers). The ability to identify new children's faces may be a critical element in the development of social competence and emotional socialization in preschool. Future studies may compare affect labeling performance in children who have not been in preschool to those in preschool.

Gender - Although the current study did not have a wide range of inhibition, girls displayed significantly higher levels of behavioral inhibition in the stranger-child interaction task than boys. Similarly, Bishop and colleagues (2003) found that parents reported girls as more behaviorally inhibited than boys in adult situations. Although they did not report gender analyses for the stranger-child interaction task, there was a strong correlation between the observation and parent report. Consistently, a greater proportion of females than males have been found to experience elevated anxiety at as young as six years old and persisting through adolescence (Lewinsohn, Gotlib, Lewinsohn, Seeley \& Allen,1998).

\section{Limitations}

The most noteworthy limitation of this study was the limited statistical power. Despite efforts of the researcher, many parents were unwilling or disinterested in completing questionnaires or having their child participate in the study during preschool. Although there was no formal feedback from parents and teachers, many parents informally cited time constraints and competing demands as prohibitory.

In addition to the small full sample, a very small portion of participating children had elevated anxiety. Only 7 children were high on latency to speak and no children were rated below a 13 out of a possible 24 on Sociability (EAS-III). From informal observations of the preschool classrooms, it is likely that more children than participated had elevated anxiety. 
While one strength of the design was the multi-informant assessment of anxiety, this may also have been a limitation. Some of these children may experience anxiety around peers, but not around parents or adults. Bishop and colleagues (2003) found that behavioral inhibition around adults loaded onto a separate factor from behavioral inhibition around peers on the Behavioral Inhibition Questionnaire. Future research may include observations of peer interaction in order to gain a more realistic sample of the child's social behaviors. Teachers also observe many samples of peer interactions over time and are valuable informants of a child's behavior. Teacher report, additional parent report measures and playground observations were included in the larger study, but were not analyzed as part of the present investigation. It is possible that the large number of measures included in the overall project may have deterred parents from participating, thus contributing to the limited sample size.

Implications and Future Directions

Few studies have been conducted to examine potential threat cues that may influence the development of anxiety in preschool children. It has been well documented that preschool is a very important period for the development of emotional competence and socialization (Denham et al., 2001; Halberstadt et al., 2001). The development of nonverbal communication interpretation skills is an important component to this process. The current results support past findings that preschool children are more skilled with certain facial stimuli than others. Although they may not be skilled at interpreting angry and fearful faces, they are able to detect differences in happy and sad faces. Since the association with anxiety remains unclear, future research should continue to investigate the development of social and emotional competence in children with elevated social anxiety in preschool. Children with social anxiety disorder often exhibit impaired social skills and social competence (Ginsberg, LaGreca \& Silverman, 1998; Stednitz \& Epkins, 2006). By detecting differences in the development of social competence early on, we may be able to better 
understand the source of the deficits later on or intervene earlier to prevent deficits from impairing functioning.

While past research has focused on facial affect interpretation skills deficits in children with social anxiety (e.g., Melfsen \& Florin, 2001), future research should also consider the possibility that children with social anxiety are highly adept at facial affect interpretation. Although not assessed in the current study, hypervigilance and heightened sensitivity to punishment may be attributable for these potential differences. More research is needed to better understand the influence of these nonverbal social cues on avoidant and escape behavior in children with social anxiety. It is possible that hypervigilant interpretation of social cues may compound with temperamental wariness to exacerbate social withdrawal and anxiety. Despite limitations, the current study has begun to explore a piece of children's social competence development in order to further the understanding of the developmental psychopathology of early childhood social anxiety. 


\section{References}

American Psychiatric Association. (1994). Diagnostic and statistical manual of mental health disorders (Fourth Edition ed.). Washington, D.C.: American Psychiatric Association.

Asendorpf, J. B. (1987). Videotape reconstruction of emotions and cognitions related to shyness. Journal of Personality and Social Psychology, 53(3), 542-549.

Asendorpf, J. B. (1989). Shyness as a final common pathway for two different kinds of inhibition. Journal of Personality and Social Psychology, 57(3), 481-492.

Ashwin, C., Wheelwright, S., \& Baron-Cohen, S. (2006). Attention bias to faces in Asperger Syndrome: a pictorial emotion Stroop study. Psychological Medicine, 36(6), 835-843.

Beidel, D. C., Turner, S. M., Hamlin, K., \& Morris, T. L. (2000). The Social Phobia and Anxiety Inventory for Children (SPAI-C): External and discriminative validity. Behavior Therapy, 31, 75-87.

Beidel, D. C., Turner, S. M., \& Wolf, P. L. (1996). Is behavioral inhibition related to the anxiety disorders? Clinical Psychology Review, 16(2), 157-172.

Biederman, J., Hirschfeld-Becker, D. R., Rosenbaum, J. F., Herot, C., Friedman, D., Snidman, N., et al. (2001). Further evidence of association between behavioral inhibition and social anxiety in children. American Journal of Psychiatry, 158, 1673-1679.

Bishop, G., Spence, S. H., \& McDonald, C. (2003). Can parents and teachers provide a reliable and valid report of behavioral inhibition? Child Development, 74(6), 1899 - 1917.

Boer, F. \& Westenberg, P.M. (1994). The factor structure of the Buss and Plomin EAS Temperament Survey (Parental Ratings) in a Dutch sample of elementary school children. Journal of Personality Assessment, 62, 537-551.

Chavira, D. A., Stein, M. B., Bailey, K., \& Stein, M. T. (2004). Child anxiety in primary care: Prevalent but untreated. Depression and Anxiety, 20, 155-164.

Cohen, J. (1992). A power primer. Psychological Bulletin, 112(1), 155-159. 
Coplan, R. J., Prakash, K., O'Neil, K., \& Armer, M. (2004). Do you "want" to play? Distinguishing between conflicted shyness and social disinterest in early childhood. Developmental Psychology, 40(2), 244-258.

Denham, S. A., Blair, K. A., DeMulder, E., Levitas, J., Sawyer, K., Auerbach-Major, S., et al. (2003). Preschool emotional competence: pathway to social competence? Child Development, 74(1), 238-256.

Egger, H. L., \& Angold, A. (2006). Common emotional and behavioral disorders in preschool children: presentation, nosology, and epidemiology. Journal of Child Psychology and Psychiatry, 47(3/4), 313-337.

Ekman, P., \& Friesen, W. V. (1976). Pictures of Facial Affect [slides]. Palo Alto, CA: Consulting Psychologists Press.

Faul. F. \& Erdfelder, E. (1992). GPOWER: A priori, post-hoc, and compromise power analyses for MS-DOS [Computer program]. Bonn, FRG: Bonn University, Dep. of Psychology.

Garcia Coll, C., Kagan, J., \& Reznick, J. S. (1984). Behavioral inhibition in young children. Child Development, 55(3), 1005-1019.

Grant, B. F., Hasin, D. F., Blanco, C., Stinson, F. S., Chou, P., Goldstein, R. B., et al. (2005). The epidemiology of social anxiety disorder in the United States: Results from the National Epidemiological Survey on Alcohol and Related Conditions. Journal of Clinical Psychiatry, 66(11), 1351-1361.

Hadwin, J. A., Donnelly, N., French, C. C., Richards, A., Watts, A., \& Daley, D. (2003). The influence of children's self-report trait anxiety and depression on visual search for emotional faces. Journal of Child Psychology and Psychiatry, 44(3), 432-444.

Halberstadt, A. G., Denham, S. A., \& Dunsome, J. C. (2001). Affective social competence. Social Development, 10(1), 79-119. 
Henderson, L., \& Zimbardo, P. (2001). Shyness, social anxiety, and social phobia. In S. G. Hofman \& P. M. DiBartolo (Eds.), From Social Anxiety to Social Phobia (pp. 46-85). Needham Heights, MA: Allyn \& Bacon.

Herba, C., Landau, S., Russell, T., Ecker, C., \& Phillips, M. L. (2006). The development of emotion-processing in children: effects of age, emotion, and intensity. Journal of Child Psychology and Psychiatry, 47(11), 1098-1106.

Hymel, S., Woody, E., \& Bowkr, A. (1993). Social withdrawal in childhood: Considering the child's perspective. In K. H. Rubin \& J. B. Asendorpf (Eds.), Social Withdrawal, Inhibition, and Shyness in Childhood (pp. 237-262). Hillsdale: Lawrence Erlbaum Associates, Publishers.

Kagan, J., Reznick, J. S., \& Snidman, N. (1990). Origins of panic disorder. In J. C. Ballenger (Ed.), Neurobiology of Panic Disorder (Vol. , pp. 71-87). New York: Wiley-Liss.

Kagan, J., Reznick, J. S., Snidman, N., Gibbons, J., \& Johnson, M. O. (1988). Childhood derivatives of inhibition and lack of inhibition to the unfamiliar. Child Development, 62, 250263.

Ladouceur, C. D., Dahl, R. E., Williamson, D. E., Birmaher, B., Ryan, N. D., \& Casey, B. J. (2005). Altered emotional processing in pediatric anxiety, depression, and comorbid anxietydepression. Journal of Abnormal Child Psychology, 33(2), 165-177.

Leve, L. D., Kim, H. K., \& Pears, K. P. (2005). Childhood temperament and family environment as predictors of internalizing and externalizing trajectories from ages 5 to 17 . Journal of Abnormal Child Psychology, 33(5), 505-520.

Lewinsohn, P. M., Gotlib, I. H., Lewinsohn, M., Seeley, J. R., \& Allen, N. B. (1998). Gender differences in anxiety disorders and anxiety symptoms in adolescents. Journal of Abnormal Psychology, 107, 109-117. 
Mathiesen, K.S., \& Tambs, K. (1999). The EAS Temperament Questionnaire: Factor structure, age trends, reliability, and stability in a Norwegian Sample. Journal of Child Psychology and Psychiatry, 40(3), 431-439.

Melfsen, S., \& Florin, I. (2002). Do socially anxious children show deficits in classifying facial expressions of emotions? Journal of Nonverbal Behavior, 26(2), 109-126.

Morris, T. L. (2001). Social phobia. In M. W. Vasey \& M. R. Dadds (Eds.), Developmental Psychopathology of Anxiety (pp. 435-458). New York: Oxford University Press.

Morris, T. L. (2004). Diagnosis of social anxiety disorder in children. In B. Bandelow \& D. J. Stein (Eds.), Social Anxiety Disorder (pp. 75-91). New York: Marcel Dekker.

Morris, T. L., Hirshfeld-Becker, D. R., Henin, A., \& Storch, E. A. (2004). Developmentally-sensitive assessment of social anxiety. Cognitive and Behavioral Practice, 11, 13-27.

Nowicki, S. Jr. \& Carton, E. (1997). The relation of nonverbal processing ability of faces and voices and children's feelings of depression of competence The Journal of Genetic Psychology, 158(3), 357-363.

Nowicki, S. Jr. \& Duke, M. P. (1994). Individual differences in the nonverbal communications of affect: The Diagnostic Analysis of Nonverbal Accuracy Scale. Special Issue: Development of Nonverbal Behavior: II. Social Development and Nonverbal Behavior. Journal of Nonverbal Behavior, 18, 9-35.

Nowicki, S. Jr. \& Mitchell, J. (1998). Accuracy in identifying affect in child and adult faces and voices and social competence in preschool children. Genetic, Social, and General Psychology Monographs, 124(1), 39-59.

Nowicki, S. Jr. \& Duke, M.P. (2003) Manual for the Receptive Tests of the Diagnostic Analysis of Nonverbal Accuracy Scale 2, Unpublished manual.

Ollendick, T., \& Hirschfeld-Becker, D. R. (2002). The developmental psychopathology of social anxiety disorder. Biological Psychiatry, 51, 44-58. 
Pellicano, E., \& Rhodes, G. (2003). Holistic processing of faces in preschool children and adults. Psychological Science, 14(6), 618-622.

Philippot, P., \& Feldman, R. S. (1990). Age and social competence in preschoolers' decoding of facial expression. British Journal of Social Psychology, 29, 43-54.

Rubin, K. H., \& Asendorpf, J. B. (1993). Social withdrawal, inhibition, and shyness in childhood. Hillsdale, NJ: Lawrence Erlbaum.

Rubin, K. H., \& Burgess, K. B. (2001). Social withdrawal and anxiety. In M. W. Vasey \& M. R. Dadds (Eds.), Developmental Psychopathology of Anxiety (pp. 407-434). New York: Oxford University Press.

Shamir-Essakow, G., Ungerer, J. A., \& Rapee, R. M. (2005). Attachment, behavioral inhibition, and anxiety in preschool children. Journal of Abnormal Child Psychology, 33(2), 131-143.

Simonian, S. J., Beidel, D. C., Turner, S. M., Berkes, J. L., \& Long, J. H. (2001). Recognition of facial affect by children and adolescents diagnosed with social phobia. Child Psychiatry and Human Development, 32(2), 137-145.

Spence, S. H. (1998). A measure of anxiety symptoms among children. Behaviour Research and Therapy, 36, 545-566.

Spence, S. H., Rapee, R. M., McDonald, C., \& Ingram, M. (2001). The structure of anxiety symptoms among preschoolers. Behaviour Research and Therapy, 39, 1293-1316.

Stednitz, J.N. \& Epkins, C.C. (2006). Girls' and mothers' social anxiety, social skills, and loneliness: associations after accounting for depressive symptoms. Journal of Clinical Child and Adolescent Psychology, 35(1), 148-154.

Taylor, M. J., Batty, M., \& Itier, R. J. (2004). The faces of development: A review of early face processing over childhood. Journal of Cognitive Neuroscience, 16(8), 1426-1442. 
Tronick, E., Als, H., Adamson, L., Wise, S., \& Brazelton, T. B. (1978). The infants' response to entrapment between contradictory messages in face-to-face interactions. Journal of the American Academy of Child Psychiatry, 17, 1-13.

U.S. Census Bureau. (2006). State and Country Quick Facts. Retrieved March 7, 2008, from http://quickfacts.census.gov/qfd/states/54000.html.

Warren, S. L., Huston, L., Egeland, B., \& Sroufe, L. A. (1997). Child and adolescent anxiety disorders and early attachment. Child and Adolescent Psychiatry, 36(5), 637-644. 


\section{TABLES}

Table 1.

Demographics for Target Variables.

\begin{tabular}{lcccc}
\hline Variable & $\underline{M}$ & $\underline{S D}$ & Minimum & Maximum \\
\hline Shyness (EASIII) & 11.63 & 4.35 & 5.00 & 20.00 \\
Sociability (EASIII) & 18.47 & 2.76 & 13.00 & 24.00 \\
Social Phobia (SPAS) & 4.09 & 2.97 & .00 & 10.00 \\
Behavioral inhibition (Latency to & & & & 180.00 \\
Speak) & 47.35 & 77.02 & .00 & 89.58 \\
DANVA2 Total (Facial Affect & & & & \\
Recognition) & 57.64 & 13.58 & 33.33 & 91.67 \\
DANVA2 Child Subtest & 61.11 & 16.57 & 29.17 & 29.17 \\
\hline DANVA2 Adult Subtest & 54.16 & 13.93 & & \\
\hline
\end{tabular}


Table 2.

Paired Samples Comparisons of Affect for DANVA2 Subscales.

\begin{tabular}{lccc}
\hline \multicolumn{1}{c}{ Measure } & M difference & $\underline{\text { SD }}$ & $\underline{t(29)}$ \\
\cline { 2 - 4 } Happy_Sad & 27.50 & 27.78 & $5.42^{\star \star}$ \\
Happy_Angry & 37.50 & 27.49 & $7.47^{\star *}$ \\
Happy_Fearful & 29.17 & 33.96 & $4.71^{\star *}$ \\
Sad_Angry & 10.00 & 30.90 & 1.77 \\
Sad_Fearful & 1.67 & 38.56 & .24 \\
Angry-Fearful & 8.33 & 29.93 & -1.53 \\
\hline ** $p<.001$ & & &
\end{tabular}




\section{Table 3.}

Paired Samples Comparisons of Affect within DANVA2 Subtest.

\begin{tabular}{|c|c|c|c|}
\hline & M difference & $\underline{\mathrm{SD}}$ & $\underline{t(29)}$ \\
\hline \multicolumn{4}{|l|}{ Adult Subtest } \\
\hline Happy-Sad & 2.03 & 1.97 & $5.64^{\star \star}$ \\
\hline Happy_Angry & 1.70 & 2.07 & $4.50^{\star \star}$ \\
\hline Happy_Fearful & 1.97 & 2.39 & $4.52^{\star \star}$ \\
\hline Sad-Angry & .33 & 2.34 & -.78 \\
\hline Sad_Fearful & .07 & 2.66 & -.14 \\
\hline Angry-Fearful & .27 & 2.07 & .71 \\
\hline \multicolumn{4}{|l|}{ Child Subtest } \\
\hline Happy_Sad & 1.27 & 1.86 & $3.74^{\star}$ \\
\hline Happy-Angry & 2.80 & 1.94 & $7.92^{\star \star}$ \\
\hline Happy_Fearful & 1.53 & 2.15 & $3.92^{\star}$ \\
\hline Sad-Angry & 1.53 & 2.22 & $3.78^{\star}$ \\
\hline Sad_Fearful & .27 & 2.53 & .58 \\
\hline Angry-Fearful & 1.27 & 2.27 & $-3.05^{\star}$ \\
\hline
\end{tabular}

${ }^{\star \star} p<.01,{ }^{\star \star \star} p<.001$. 


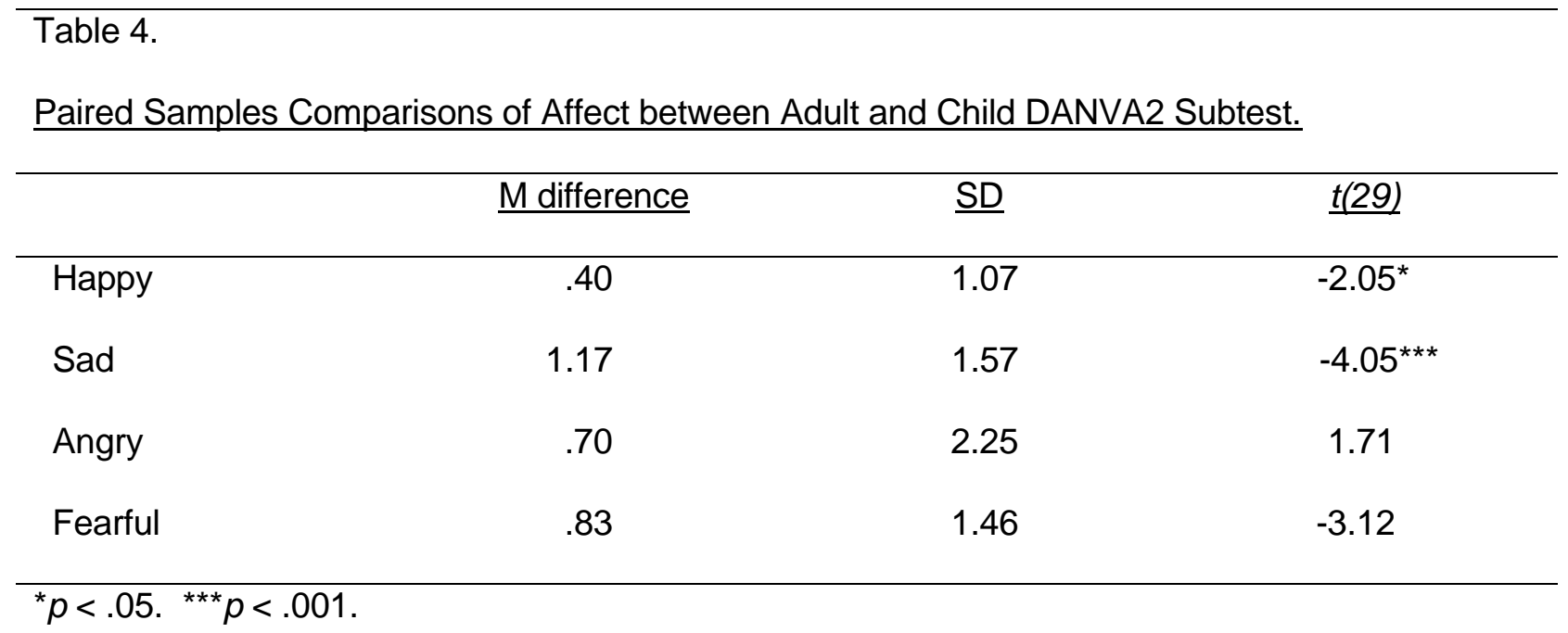


Table 5.

Analysis of Variance for Demographic Variables by DANVA2 Accuracy.

\begin{tabular}{|c|c|c|c|c|c|}
\hline & $\underline{\mathrm{n}}$ & $\underline{\mathrm{M}}$ & $\underline{\mathrm{SD}}$ & $\underline{F}$ & $\underline{p}$ \\
\hline Age & & & & 1.41 & .24 \\
\hline 4 year olds & 26 & 56.49 & 14.22 & & \\
\hline 5 year olds & 4 & 65.10 & 3.56 & & \\
\hline Gender & & & & .52 & .47 \\
\hline Boys & 15 & 55.83 & 11.25 & & \\
\hline Girls & 15 & 59.44 & 15.77 & & \\
\hline Child's Ethnicity & & & & 1.74 & .19 \\
\hline Caucasian & 27 & 58.49 & 13.49 & & \\
\hline Hispanic & 1 & 33.33 & -- & & \\
\hline Other & 2 & 58.33 & 2.95 & & \\
\hline
\end{tabular}


Table 6.

Means, Standard Deviation, and Intercorrelations for Facial Affect Recognition and Social

Anxiety Variables

\begin{tabular}{|c|c|c|c|c|c|c|}
\hline Variable & $\underline{\mathrm{M}}$ & $\underline{\mathrm{SD}}$ & 1 & 2 & 3 & 4 \\
\hline DANVA2 & 58.19 & 13.48 & .10 & -.23 & $.33^{*}$ & -.01 \\
\hline \multicolumn{7}{|l|}{ Independent variable } \\
\hline 1. Shyness (EASIII) & 11.55 & 4.40 & -- & $-.67^{\star \star}$ & $.66^{\star \star}$ & .26 \\
\hline 2. Sociability (EASIII) & 18.55 & 2.77 & & -- & $-.44^{*}$ & -.12 \\
\hline 3. Social Phobia (SPAS) & 4.03 & 3.00 & & & -- & -.08 \\
\hline $\begin{array}{l}\text { 4. Behavioral inhibition } \\
\text { (Latency to Speak) }\end{array}$ & .24 & .44 & & & & -- \\
\hline
\end{tabular}




\section{Table 7.}

$\underline{\text { Regression Analysis Summary for Social Anxiety Variables Relating to Facial Affect }}$

$\underline{\text { Recognition }}$

\begin{tabular}{lccc}
\multicolumn{1}{c}{ Variable } & $\underline{\mathrm{B}}$ & $\underline{\mathrm{SEB}}$ & $\underline{\beta}$ \\
\hline Shyness & -2.12 & 1.07 & -.69 \\
Social withdrawal & -2.25 & 1.29 & .46 \\
Social anxiety & 2.75 & 1.15 & $.61^{*}$ \\
Behavioral inhibition & 9.24 & 6.80 & .30 \\
\hline${ }^{*} p<.05$. & &
\end{tabular}




\section{FIGURES}

Figure 1.

Gender by Latency to Speak.

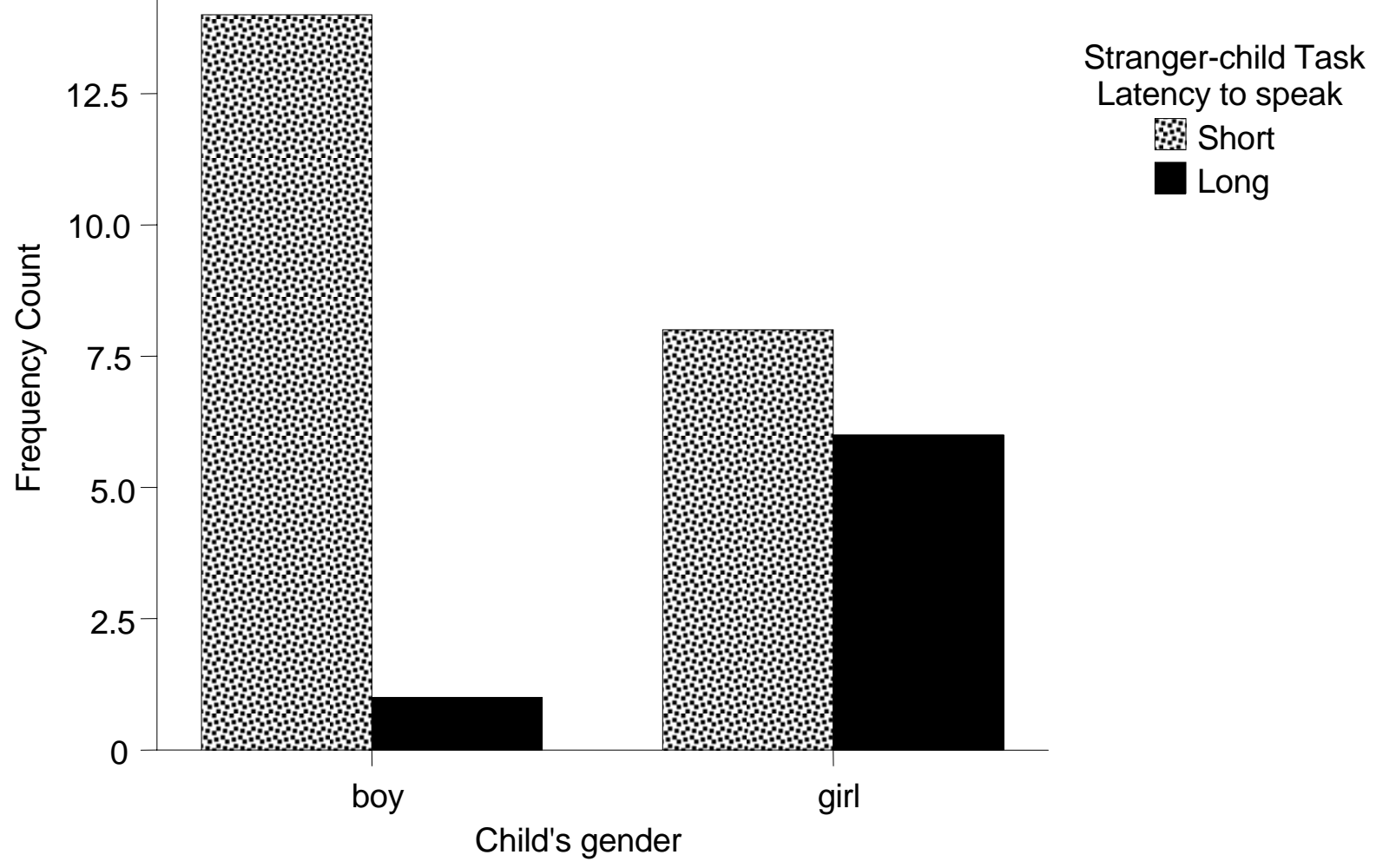


Appendix A

Examples of Child Facial Stimuli from the DANVA2

Sad:

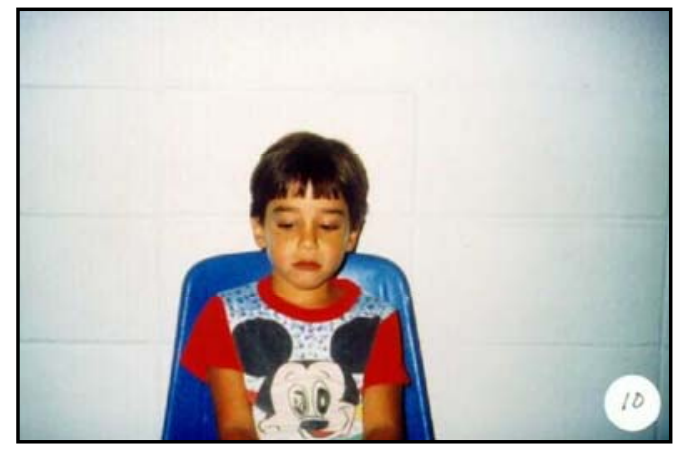

Scared:

Happy:
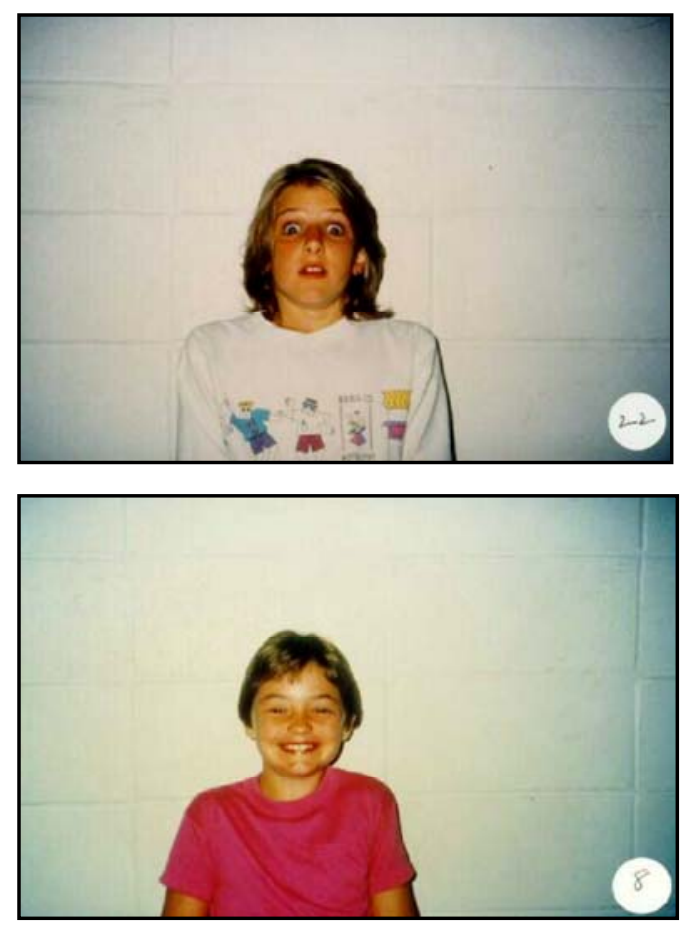

Angry:

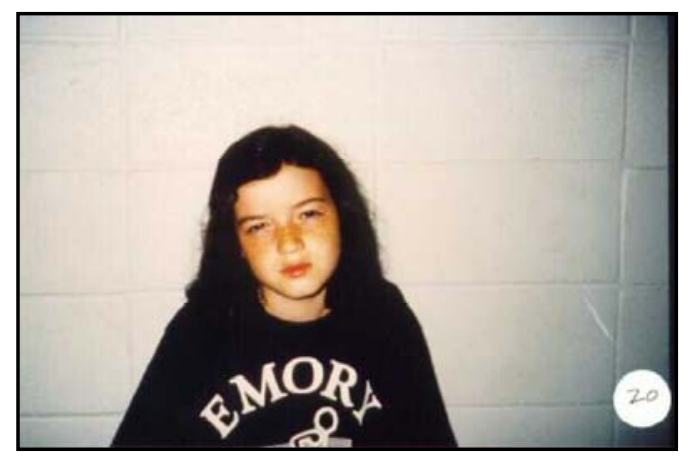


Appendix B

Demographic Questionnaire

ABOUT YOU AND YOUR FAMILY

Your name:

Your child's name:

Your age:

Child's Age:

Your relationship to the child:

Child's Sex: __Boy __ Girl

Your ethnicity:

Your child's ethnicity:

Caucasian

Caucasian

African American

African American

Hispanic

Asian American

Hispanic

Native American

Asian American

Other:

Native American

Other:

Occupation: Please provide your job position or title, NOT the name of your employer. For example, if you are a teacher at Morgantown High school, please state "high school teacher." If you are retired, please state "retired" as well as your prior occupation. If you do not work outside the home, please state "stay at home parent" or "unemployed."

What is your occupation?

Highest Level of Education Completed:

(please be specific)

Did not complete high school

High School

Some College

College Degree

Graduate Degree

Please complete the following information about your spouse (if applicable):

Your spouse's age:

Your spouse's occupation:

Highest level of education completed by your spouse:

Did not complete high school

High School

Some College

College Degree

Graduate Degree
Your spouse's ethnicity:

Caucasian

African American

Hispanic

Asian American

Native American

Other: 